\title{
Advances in molecular mechanisms of interaction between Mycobacterium tuberculosis and lung cancer: a narrative review
}

\author{
Kunlong Xiong ${ }^{1,2 \#} \wedge$, Wenwen Sun ${ }^{1,2 \#}$, Yayi $\mathrm{He}^{2,3}, \operatorname{Lin}_{\text {Fan }}{ }^{1,2} \wedge$ \\ ${ }^{1}$ Shanghai Clinical Research Center for Infectious Disease (Tuberculosis), Department of Tuberculosis, Shanghai Key Laboratory of Tuberculosis, \\ Shanghai Pulmonary Hospital, Tongji University School of Medicine, Shanghai, China; ${ }^{2}$ Department of Tuberculosis, Tongji University, Shanghai, \\ China; ${ }^{3}$ Department of Medical Oncology, Shanghai Pulmonary Hospital, Tongji University Medical School Cancer Institute, Tongji University \\ School of Medicine, Shanghai, China \\ Contributions: (I) Conception and design: Y He; (II) Administrative support: Y He, L Fan; (III) Provision of study materials or patients: K Xiong, W \\ Sun; (IV) Collection and assembly of data: K Xiong; (V) Data analysis and interpretation: K Xiong, W Sun; (VI) Manuscript writing: All authors; (VII) \\ Final approval of manuscript: All authors. \\ \#These authors contributed equally to this work. \\ Correspondence to: Yayi He. Department of Medical Oncology, Shanghai Pulmonary Hospital, Tongji University Medical School Cancer Institute, \\ Tongji University School of Medicine, No. 507 Zhengmin Road, Shanghai 200433, China. Email: yayi.he@tongji.edu.cn; Lin Fan. Shanghai Clinical \\ Research Center for Infectious Disease (Tuberculosis), Department of Tuberculosis, Shanghai Key Laboratory of Tuberculosis, Shanghai Pulmonary \\ Hospital, Tongji University School of Medicine, Shanghai 200433, China. Email: fanlinsj@163.com.
}

Objective: We systematically review the molecular mechanism of the interaction between lung cancer (LC) and tuberculosis (TB), and put forward the existing problems in order to provide suggestions for early intervention and future research direction.

Background: TB and LC are two global public health problems affecting human health. LC is the main cause of cancer-related death worldwide and TB is one of the leading causes of death among infectious diseases, especially in resource-poor areas. Previous studies have suggested that a history of TB may be associated with an increased risk of LC. With the improvement of LC treatment, the occurrence of pulmonary tuberculosis in the course of LC treatment is also frequently reported recently.

Methods: The molecular immunological mechanisms of interaction between LC and TB, and related epidemiological literature are reviewed. The research progress and problems to be solved are summarized.

Conclusions: Chronic inflammation, immune abnormalities, scar formation, gene mutations and drug effects caused by TB may be associated with the occurrence of LC induced by abnormalities in various molecular pathways. LC and decreased immunity during treatment may also increase the risk of latent TB activation or new TB infection through immune pathways. Data on dual burden areas of TB and LC are still lacking, and more clinical studies are needed to elucidate the association.

Keywords: Tuberculosis (TB); lung cancer; inflammation; epidermal growth factor receptor (EGFR); PD-1; microflora

Submitted Jun 04, 2021. Accepted for publication Sep 09, 2021.

doi: $10.21037 /$ tlcr-21-465

View this article at: https://dx.doi.org/10.21037/tlcr-21-465

\footnotetext{
^ ORCID: Kunlong Xiong, 0000-0002-3312-227X; Lin Fan, 0000-0002-9411-496X.
} 


\section{Introduction}

Tuberculosis (TB), caused by the bacillus Mycobacterium tuberculosis (MTB), is one of the main sources of morbidity and mortality from infectious disease (ranking even higher than HIV), infecting nearly a quarter of the whole population worldwide, and causes more than 1.4 million deaths in 2019, according to the Global Tuberculosis Report 2020 from World Health Organization (WHO) (1). MTB mainly infected the lung, known as pulmonary tuberculosis (PTB). Most people infected with MTB remain asymptomatic and without any observed lesions, known as latent tuberculosis infection (LTBI), with a lifetime risk of developing active TB of about $5-10 \%(1)$.

Lung cancer (LC) also remains the leading cause of tumorrelated death globally. There were about 2.2 million new cases and 1.8 million deaths caused by LC in 2020 (2). LC is divided into small cell lung cancer (SCLC) and non-small cell lung cancer (NSCLC). NSCLC accounts for 80-85\% of LC, including adenocarcinoma, squamous cell carcinoma, and large cell carcinoma (3-5). In the last two decades, the 5-year survival rate of NSCLC has been lower than $20 \%$, while the 5 -year survival rate of SCLC is close to 5\% (5-7).

As an important factor in causing tumors, carcinogenic infections are responsible for about $15.4 \%$ (2.2 million) of 14 million new cases of cancer in $2012(8,9)$. And with the improvement of the treatment of LC, the wide application of immunotherapy and the prolonged survival of LC patients, the co-existence of TB and LC is becoming more common in clinical practice, especially in developing countries with high burden of TB. Previous study had divided the coexistence of TB and LC into three types: (I) no relationship between PTB and LC; (II) LC developed on the basis of tuberculous lesions, induced by bronchial/alveolar malformations and epithelial dysplasia; (III) reactivation of TB during LC progression and treatment (10).

Cough, expectoration, hemoptysis, chest pain, shortness of breath, fever, and abnormal radiological findings are common symptoms of both $\mathrm{LC}$ and TB, leading to a challenge in the diagnosis of the diseases. Systemic chemotherapy and immunotherapy commonly accepted in LC are highly correlated with the development of TB (11). Previous studies have shown that a history of PTB is associated with an increased risk of LC (12-19), or the survival and mortality of LC $(20,21)$. TB, as a risk factor for LC has been widely studied and its pathogenesis is complex, mainly focusing on chronic inflammatory stimulation, immune dysfunction, scar calcification, gene mutation, etc., but the specific mechanism has not been fully elucidated. In the present study, the molecular mechanism and possible interaction between LC and TB were reviewed, the existing problems were proposed, in order to provide the basis for early identification and intervention of patients with LC complicated PTB, especially in areas with high TB burdens.

We present the following article in accordance with the Narrative Review reporting checklist (available at https:// dx.doi.org/10.21037/tlcr-21-465).

\section{Epidemiology correlations between TB and LC}

There were about 10 million TB patients in 2019 globally, especially in India and China, the highest and the secondhighest TB burden countries, with an estimated 2.6 or 0.8 million TB incidence, respectively (1). A large amounts of epidemiological data have showed that PTB could be closely related to LC (shown in Table 1). Cicenas et al. (10) found that PTB co-exists with $\mathrm{LC}$, which is a rare clinical observation compared to the single incidence of PTB or LC, about $2.1 \%$ operated LC patients were diagnosed with complicated PTB. Everatt et al. (12) studied the risk of LC in a cohort of 21,986 PTB patients in Lithuania. The results showed that during follow-up, $477 \mathrm{~TB}$ patients developed LC, and patients with a history of TB had a 3.5-fold increased risk of LC. There were also some other retrospective cohort or prospective longitudinal studies showed the pre-existing PTB associated with an increased risk of LC (13-17).

Several meta-analyses were also performed to estimate the association between TB and LC. Liang and collogues (18) performed a systematic review and metaanalysis of 37 case-control and 4 cohort studies to assess the association between LC risk and pre-existing TB. The results showed pre-existing $\mathrm{TB}$ had a significant association with the increased LC risk [relative risk (RR): 1.7; 95\% confidence interval (CI): 1.5-2.0]. Moreover, the elevated LC risk persisted 2-fold higher after over two decades since TB was diagnosed. Brenner et al. (19) conducted a meta-analysis to survey the epidemiologic clues about the correlation between pre-existing $\mathrm{TB}$ and the increased risk of LC, after analyzing for 30 studies, a significantly increased LC risk was found in patients with pre-existing TB compared to the subjects without preexisting TB (RR: 1.8; 95\% CI: 1.5-2.1). A meta-analysis performed by Leung et al. (9) including 52,480 cancer cases showed that TB was associated with LC (RR: 1.7; $95 \%$ 
Table 1 Published studies about epidemiology correlations between tuberculosis and lung cancer

\begin{tabular}{|c|c|c|c|c|c|}
\hline Investigator (year) & $\begin{array}{l}\text { Cohort size/number } \\
\text { of controls }\end{array}$ & Methods & Results & Conclusions & Ref. \\
\hline Leung (2020) & $\begin{array}{l}52,480 \text { cancer } \\
\text { cases }\end{array}$ & Meta-analysis & $\begin{array}{l}\text { LC RR was } 1.7 \text { (95\% Cl: } 1.5-2.0) \text { in TB } \\
\text { patients. }\end{array}$ & $\begin{array}{l}\text { TB was associated with } \\
\text { lung cancer. }\end{array}$ & (9) \\
\hline Everatt (2016) & 21,986 TB patients & $\begin{array}{l}\text { Retrospective } \\
\text { study }\end{array}$ & $\begin{array}{l}477 \text { TB patients developed LC, and } \\
3.5 \text {-fold increase risk of LC in subjects } \\
\text { with a history of TB. }\end{array}$ & $\begin{array}{l}\text { The excess risk of LC in } \\
\text { the TB cohort is associated } \\
\text { with multiple factors. }\end{array}$ & (12) \\
\hline Wu (2011) & $\begin{array}{l}5,657 \text { patients with } \\
\text { pre-existing TB, } \\
23,984 \text { controls }\end{array}$ & $\begin{array}{l}\text { Retrospective } \\
\text { cohort study }\end{array}$ & $\begin{array}{l}\text { LC IRR was } 1.8(95 \% \mathrm{Cl}: 1.3-2.3) \text { in PTB } \\
\text { patients. }\end{array}$ & $\begin{array}{l}\text { PTB is associated with an } \\
\text { increased risk of LC. }\end{array}$ & (14) \\
\hline Zheng (1987) & $\begin{array}{l}1,405 \text { LC patients, } \\
1,495 \text { controls }\end{array}$ & $\begin{array}{l}\text { Prospective } \\
\text { longitudinal } \\
\text { study }\end{array}$ & $\begin{array}{l}\text { LC OR was } 1.5 \text { in TB cohort and } \\
\text { remained } 2.5 \text {-fold higher after the TB } \\
\text { diagnosis within the past } 20 \text { years. }\end{array}$ & TB may predispose to LC. & $(16)$ \\
\hline Shiels (2011) & $\begin{array}{l}273 \text { male smokers } \\
\text { with TB, } 28,860 \\
\text { male smokers with } \\
\text { non-TB }\end{array}$ & $\begin{array}{l}\text { Prospective } \\
\text { longitudinal } \\
\text { study }\end{array}$ & $\begin{array}{l}\text { LC HR was } 2 \text { in TB patients ( } 95 \% \mathrm{Cl} \text { : } \\
1.5-2.7) \text {, and LC risk was highest at about } \\
2 \text { years after TB diagnosis (HR: } 5.0 ; 95 \% \\
\mathrm{Cl} \text { : } 3.0-8.5) \text {, but the risk remained raised } \\
\text { at the longer latencies (HR: } 1.5 ; 95 \% \mathrm{Cl} \text { : } \\
1.1-2.2) \text {. }\end{array}$ & $\begin{array}{l}\text { TB is associated with } \\
\text { increased LC risk in male } \\
\text { smokers. }\end{array}$ & $(17)$ \\
\hline Brenner (2011) & $\begin{array}{l}30 \text { studies, } 82,716 \\
\text { cases }\end{array}$ & Meta-analysis & $\begin{array}{l}\text { LC RR was } 1.8(95 \% \mathrm{Cl}: 1.5-2.1) \text { in } \\
\text { pre-existing TB patients. }\end{array}$ & $\begin{array}{l}\text { PTB is associated with an } \\
\text { increased risk of LC. }\end{array}$ & (19) \\
\hline Littman (2004) & 17,698 smokers & $\begin{array}{l}\text { Prospective } \\
\text { longitudinal } \\
\text { study }\end{array}$ & $\begin{array}{l}\text { Pre-existing of pulmonary emphysema or } \\
\text { chronic bronchitis, rather than TB, was } \\
\text { more likely to be associated with LC in } \\
\text { smoking subjects. }\end{array}$ & $\begin{array}{l}\text { Pre-existing TB had no } \\
\text { correlation with LC. }\end{array}$ & (22) \\
\hline Engels (2009) & $\begin{array}{l}246 \text { TB patients, } \\
42,176 \text { no-TB } \\
\text { cases }\end{array}$ & $\begin{array}{l}\text { Retrospective } \\
\text { cohort study }\end{array}$ & $\begin{array}{l}\text { LC HR was } 9.7 \text { ( } 95 \% \text { Cl: } 4.8-19) \text { in TB } \\
\text { patients within } 5 \text { years after TB diagnosis, } \\
\text { the mortality of LC was higher in TB } \\
\text { patients than in LC patients without a } \\
\text { history of TB ( } 25 \text { vs. } \\
3.1 \text { per } 1,000 \text { person-years). }\end{array}$ & $\begin{array}{l}\text { TB was an important risk } \\
\text { factor for LC, and LC } \\
\text { mortality was higher in TB } \\
\text { patients. }\end{array}$ & (20) \\
\hline
\end{tabular}

Table 1 (continued) 
Table 1 (continued)

\begin{tabular}{|c|c|c|c|c|c|}
\hline Investigator (year) & $\begin{array}{l}\text { Cohort size/number } \\
\text { of controls }\end{array}$ & Methods & Results & Conclusions & Ref. \\
\hline Heuvers (2012) & $\begin{array}{l}214 \text { LC patients, } \\
7,769 \text { subjects } \\
\text { without LC }\end{array}$ & $\begin{array}{l}\text { Retrospective } \\
\text { cohort study }\end{array}$ & $\begin{array}{l}13 \text { of the } 214 \text { LC patients was reported } \\
\text { to have a history of TB, and the survival } \\
\text { of the LC patients with pre-existing TB } \\
\text { was significantly shorter (HR: } 2.4,95 \% \\
\mathrm{Cl}: 1.1-4.9 \text { ) than those without with a } \\
\text { difference in means of } 311 \text { days. }\end{array}$ & $\begin{array}{l}\text { Pre-existing TB may be an } \\
\text { important prognostic factor } \\
\text { for the survival of LC. }\end{array}$ & $(21)$ \\
\hline Su (2016) & $\begin{array}{l}11,522 \text { LTBI } \\
\text { subjects, } 46,088 \\
\text { matched subjects }\end{array}$ & $\begin{array}{l}\text { Retrospective } \\
\text { cohort study }\end{array}$ & LC HR was 2.7 in TB contacts. & $\begin{array}{l}\text { LTBI cohorts had an } \\
\text { increased lung cancer } \\
\text { incidence. }\end{array}$ & (23) \\
\hline
\end{tabular}

TB, tuberculosis; LC, lung cancer; HR, hazard ratio; $\mathrm{Cl}$, confidence interval; IRR, incidence rate ratio; OR, odds ratio; RR, relative risk; LTBI, latent tuberculosis infection.

CI: 1.5-2.0). What's more, LTBI cohort was also reported with an increased incidence of LC compared to comparison cohort [hazard ratio (HR): 2.7] (23).

Although most of related studies showed an increased LC risk among individuals with PTB, a study (22) in North America involved 17,698 smokers reported that the preexisting of pulmonary emphysema or chronic bronchitis, rather than other lung diseases (such as TB, asbestosis, asthma), was more likely to be associated with LC in smoking subjects (adjusted HR: 1.3; 95\% CI: 1.1-1.5).

In addition, whether TB was associated with subsequent LC survival and mortality was also analyzed by some studies. A retrospective cohort study (20) in China recruited 42,422 farmers to evaluate the relationship between PTB and the mortality of subsequent LC. The results showed that the mortality of LC was higher in patients with PTB history (25 per 1,000 person-years) than in LC patients without a history of PTB (3.1 per 1,000 person-years), which was especially obvious within the first 5 -year after the diagnosis of PTB (HR ranging from 6.7 to13) and remained robust within the 5-9.9 years (HR: 3.4; 95\% CI: 1.3-9.1), or more than 10 years (HR:3.0; 95\% CI: 1.3-7.3). Based on the data from "The Rotterdam Study" (24), a population-based retrospective cohort study, with 214 LC patients and 7,769 subjects without LC included, Heuvers et al. (21) attempted to examine whether pre-existing РТВ was an independent risk factor for LC survival. The results showed that 13 of the 214 LC patients was reported to have a history of PTB, and the survival of the LC patients with pre-existing PTB was significantly shorter (HR: 2.4, 95\% CI: 1.1-4.9) than those without with a difference in means of 311 days (Table 1).

\section{Mechanisms of chronic inflammation elicited by MTB infection in tumorigenesis}

Long-term pathogen-induced chronic inflammatory stimulation will increase the risk of cancer. Helicobacter pylori, hepatitis virus, human papillomavirus and EpsteinBarr virus are common susceptible carcinogens (9). The continuous inflammatory stimulation and tissue damage/ repair caused by MTB infection are also important reasons for the development of LC. After infection, alveolar macrophages endocytose invasive MTB and sequestrate them in the phagosome (25). However, MTB has evolved special mechanisms to escape the phagosome and persist in cytoplasm of macrophages, leading to the formation of granulomas (26). Since the ability of immune cells (e.g., macrophages, T cells, B cells), which is recruited by MTB-infected macrophages within or around the granulomas, to kill mycobacterium can resist the aggressive invasiveness of MTB, the growth of mycobacteria is slowed down and the non-replicating bacteria in the macrophage remain dormant, leading to persistent chronic inflammation with more vascularized tissues surrounding, recruited macrophages, and T cells (27-29). Respiratory inflammation may persist for several months before PTB diagnosis and during the anti-TB treatment. Inflammatory lung diseases or lung infections (such as PTB, bacterial pneumonia) have been reported to be the elevated risks of LC (12-19,30). After invading, MTB induces the production of tumor necrosis factor (TNF), interferongamma (IFN- $\gamma$ ), interleukins in host. TNF and IL-6 promote antiapoptotic genes expression through the nuclear factor kappa B (NF- $\mathrm{B}$ ) pathway in pulmonary epithelial cells, contributing to the development of 
cancer (30-32).

Tumor microenvironment (TME), which is orchestrated primarily by infiltrating inflammatory cells, plays a role in promoting cell proliferation, survival and migration, leading to the tumorigenesis (33). TME and TB granulomas share the same central theme, hijacked macrophage polarization programs and exhausted phenotypes of $\mathrm{T}$ cells (28). There are numerous immune checkpoints enriched in exhausted T cells, such as PD-1, LAG-3, TIM-3, and CTLA-4 (34), which play a central role in $\mathrm{T}$ cell response inhibition. Relieving the immunosuppressive factors in the TME is beneficial to restore the functional inhibition of exhausted $\mathrm{T}$ cells and tumor therapy. Studies have reported that PD-1/ PD-L1 targeted blocking antibodies are entering first-line therapy in recent years, for the vibrant survival benefits they have offered to NSCLC patients $(35,36)$. Thus, the exhausted $\mathrm{T}$ cell phenotype induced by MTB contributes to the development of tumors.

Cancer formation develops from "initiation" and "promotion", and these two subthreshold tumor states are usually caused by chemical or viral carcinogens, leading to somatic cell changes (37). The "initiation" state involves irreversible changes in DNA that can persist in normal cells until the second state "promotes" occurs. The "promoter" state can arise from chemical irritants exposure of initiated cells, such as the release of phobol esters due to chronic inflammation. The "promoter" state promotes cell proliferation, recruitment of inflammatory cells, production of reactive oxygen species (ROS), oxidative damage of DNA, and reduction of DNA repair (33). Chronic inflammation induced by MTB promotes cell death, cell proliferation, excessive ROS production, DNA damage and DNA repair, which persist in chronic inflammatory tissues, resulting in loss of normal growth control of DNA replication and proliferation of cells. The level of ROS is increased in different types of tumor cells, and the increased ROS is believed to cause DNA damage, generate mutagenic mediators (such as peroxynitrite), promote genetic instability, and thus carcinogenesis (38-40).

Substantial and prolonged pulmonary inflammation induced by TB leads to repeated tissue damage and repair, forming fibrotic scarring, which is associated with the increased LC risk $(17,41,42)$. Tuberculous fibrosis may enhance the tumorigenic potential of lung cells through the NOX4-autophagy axis was documented in mouse model recently (43). Inflammatory monocytes (IMs) (referred as to phenotype "CCR $2{ }^{\text {high }} \mathrm{CD} 14^{+} \mathrm{CD} 16^{\text {low" }}$ in humans) are found in LC and play a crucial role in tumor-promoting and scar tissue formation (44-46). Lung squamous cell carcinomas (SCC) is a major subtype of LC, characterized by low survival rate and dense recruitment of the IMs, which is adequate for the distant metastasis of SCC (46). Tumors recruit IMs through secretion of monocyte chemotactic protein-1 (CCL-2) (46). Increased CCL-2 is also found in PTB patients (47). IMs can differentiate into dendritic cells (DCs) or tumor-associated macrophages (TAMs), which can be classified as M2-like macrophages and play an important role in tumor-promoting (45,48-52). For example, vascular endothelial growth factor A (VEGF-A), IL-6 and epidermal growth factor (EGF), Factor XIIIA produced by IM-derived TAMs play important roles in promoting the stemness and migration feature of tumor cells, paracrine responses in the TME, and SCC cells invasion and metastases trough the scaffold offered by the cross-linking of fibrin, respectively. In conclusion, chronic inflammation induced by MTB may be involved in the development of LC through exhausted T cell phenotype, DNA damage and repair, ROS production, tuberculous granuloma, tuberculous fibrosis, and IMs infiltration (Figure 1).

\section{M2 polarization of macrophages induced by MTB may lead to LC}

TAMs are the main component of infiltrated immune cells in TME. Macrophages are generally categorized to M1 (drive inflammation) or M2 (anti-inflammatory and promoting to wound healing) types, and TAMs are typically polarized into M2-like phenotype (52-57). The M1-like macrophages are induced by Th1 cytokines [including colony stimulating factor 2 (CSF-2), TNF- $\alpha, \mathrm{IFN}-\gamma]$ or bacterial lipopolysaccharide, a toll-like receptor ligand $(58,59)$. M1-like macrophages respond to infected pathogens and cancer cells by secreting ROS and some cytokines (such as TNF- $\alpha$, IL-6, IL-23, and IL-12) to response against infected pathogens and cancer cells $(60,61)$. Thus, an increased number of M1-like macrophages is usually associated with a favorable prognosis of cancer disease. M2-like macrophages, whose polarization is induced by Th2-derived cytokines (including IL-4, IL-13) or immunosuppressants (such as IL-10, TGF- $\beta$, glucocorticoids), are known to suppress inflammatory reaction and promote tissue regeneration through immunotolerance, immune modulation, dead cell debris scavenging and tissue remodeling $(62,63)$.

In cancer, M2-like macrophages contribute to increased expression of angiogenesis and immunosuppressive molecules (including IL-10, PD-L1, and TGF- $\beta$ ) that 


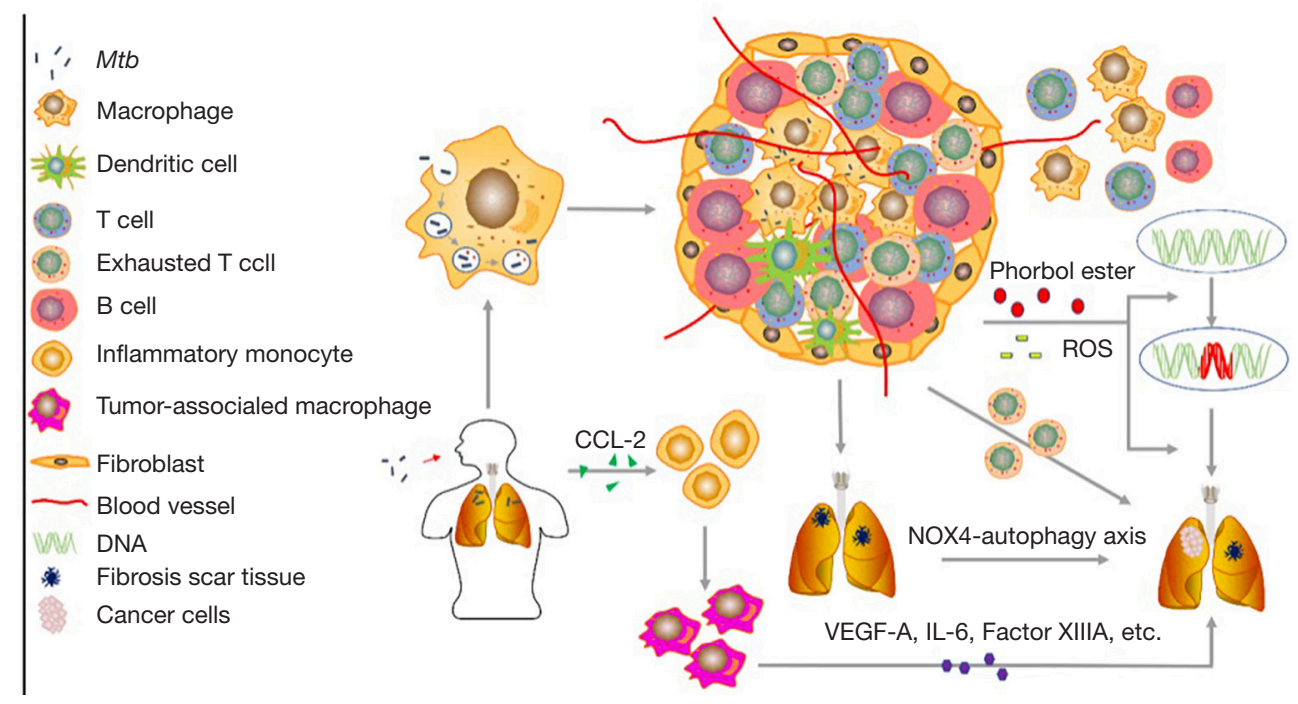

Figure 1 Chronic inflammation elicited by Mycobacterium tuberculosis (MTB) may be involved in the development of lung cancer (LC) through exhausted T cell phenotype, DNA damage and repair, reactive oxygen species (ROS) production, tuberculosis (TB) granuloma, tuberculous fibrosis formation and IMs infiltration. In the early stage of infection, the endocytosed infected MTB escape the phagosome of alveolar macrophages leads to the formation of granuloma, which vascularizes surrounding tissues and recruits immune cells, contributes to the prolonged inflammation. The exhausted $\mathrm{T}$ cells enriched in granuloma and the chronic inflammation induced ROS and chemical irritants releasing promote the occurrence of LC. There are a large number of immune checkpoints expression in exhausted T cells, which play a central role in inhibiting the $\mathrm{T}$ cell response and facilitating tumor progression. LC can also develop from fibrotic scar induced by MTB-induced lengthy pulmonary inflammation through mechanisms like NOX4-autophagy axis enhances the tumorigenic potential of lung cells. The TB patients have an increased expression level of monocyte chemoattractant protein-1 (CCL-2), which can recruit inflammatory monocytes (IMs). IMs can differentiate into tumor-associated macrophages (TAMs), and IMs-derived TAMs contribute to tumorigenesis through vascular endothelial growth factor A (VEGF-A), IL-6 and epidermal growth factor (EGF) or Factor XIIIA.

promote tumor cell growth (58). A high degree of M2like TAMs infiltration is closely associated with tumor progression, invasion, metastasis, and resistance to cancer therapy (64-66). Xu et al. (67) found that TAMs, with M2like phenotype that had a significant effect on external therapy resistance of anti-Her2/neu antibody therapy, can be skewed to M1-like polarized phenotype when anti-Her2/ neu antibody therapy combined with targeted delivery of IL-21, and then overcomes anti-Her2/Neu resistance.

The polarization state of macrophage is not fixed, other cells or pathogens can alter the polarization state through multiple signals produced by them (68). In the early phase of $\mathrm{PTB}$, the $\mathrm{M} 1$ phenotype of macrophages is upregulated, while the M2 phenotype is dominant in the intermediate and late stages (63). M1-like polarization of macrophages is included with enhanced phagocytosis, increased secretion levels of pro-inflammatory cytokines, and elevated production of nitric oxide (NO) in nonspecific host immune response to infected intracellular bacteria $(63,69)$. The susceptibility and progression of PTB was reported to be associated with elevated levels of type-2 inflammatory response signals such as IL-4, IL13 or IL-10 (56). Successful treatment of PTB shifts the inflammatory atmosphere in infected patients from type-2 back to type-1 $(70,71)$. In addition, it has been reported that NO can strongly inhibit the proliferation of human A431 tumor cells (72). Therefore, M1 phenotype polarization of macrophages is deleterious for both tumor cells and MTB. To counteract the "detrimental" effects of M1-like macrophages, MTB blocks M1 polarization through the bystander effect mediated transcription inhibition of IFN- $\gamma$ that IL-6 participates in Ref. (73), leading to the elevated level of M2-like macrophages in TB. M2-like polarization of macrophages, which is characterized by low IL-12 expression and high IL-10 expression, drives the TME skewing to an anti-inflammatory state $(28,53)$. M2 macrophages can help recruit Tregs (regulatory T-cells) into TME through CCR4 (C-C chemokine receptor 4) (74). M2 TAMs are reported to 


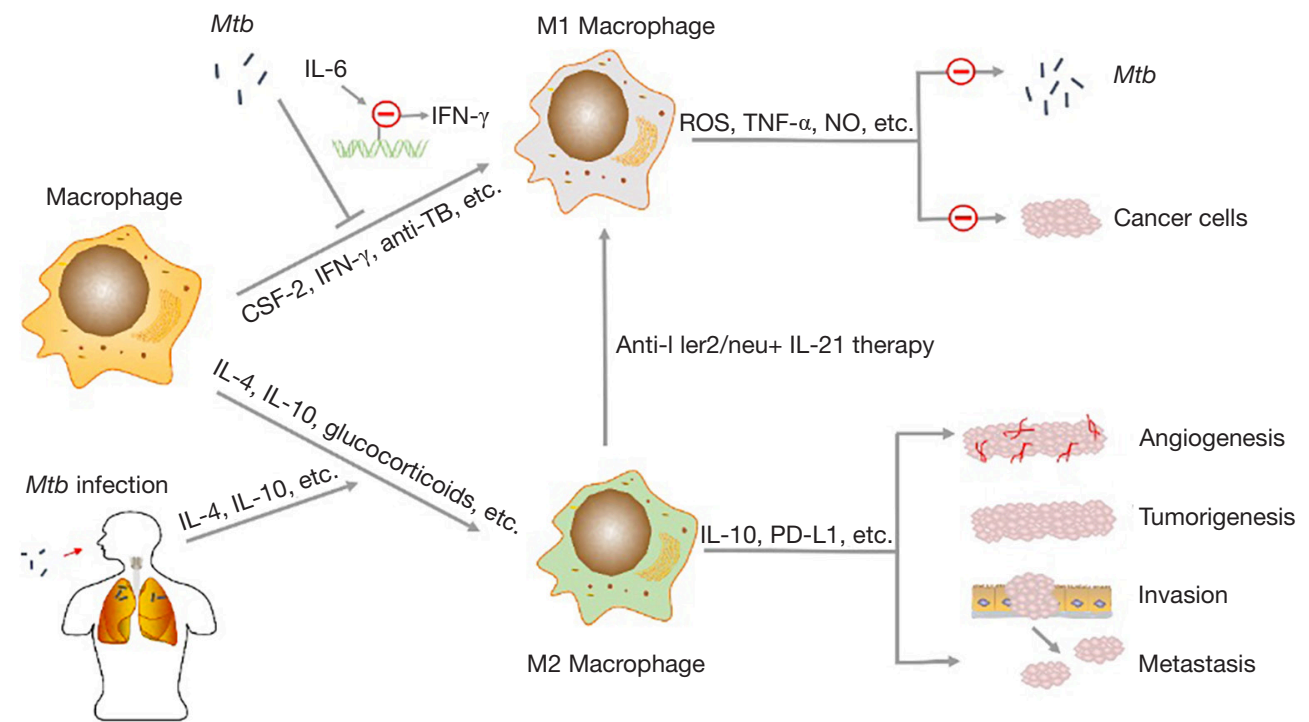

Figure 2 M2 polarization of macrophages induced by Mycobacterium tuberculosis (MTB) in lung cancer (LC): macrophages are generally categorized to M1 or M2 phenotype. M1-like macrophages, induced by Th1 cytokines such as colony stimulating factor (CSF)-2, TNF- $\alpha$, and IFN- $\gamma$, are associate with pro-inflammatory and response against infected pathogens and cancer cells through ROS, TNF- $\alpha$, IL-6, NO, etc. M2-like macrophages, induced by Th2 cytokines such as IL-4 and IL-13, contribute to angiogenesis and increased expression of immunosuppressive molecules to promote tumor cell growth, invasion, metastases. The M2 phenotype dominates in the intermediate and late phases of tuberculosis (TB), and raised levels of type-2 inflammatory response signals such as IL-4, IL-13 or IL-10 raised in TB patients, leading to the occurrence and progression of LC. MTB develops a relevant strategy to block M1 polarization through IL-6 involved bystander effect-mediated inhibition of the transcription of IFN- $\gamma$. While combining anti-Her $2 /$ neu antibody with targeted delivery of can skew M2-like macrophages to M1 phenotypes, and anti-TB therapy can shift the inflammatory atmosphere type-2 back to type-1, thus increase M1-like macrophages in PTB patients.

express more PD-L1 and CTLA4, the immune checkpoints for CTLs (cytotoxic T-cells), weakening the ability of CTLs to eliminate cancer cells $(68,75)$. In addition, M2 TAMs express TGF- $\beta$, EGF, the molecules play roles in inhibiting apoptosis and prompting tumor cells proliferation to affect tumor progress directly (68). In conclusion, the M2-like phenotype polarization of macrophages, which is dominated in the intermediate and late phases of TB, may be one of the causes of pulmonary neoplasia (Figure 2).

\section{TB may be associated with LC through epidermal growth factor receptor (EGFR) gene mutations and epiregulin production}

EGFR, a transmembrane glycoprotein that belongs to the HER family (human EGFR related family), participates in numerous biological processes, cell proliferation and survival included, and the mutations of EGFR gene are the first identified driver mutation in LC $(76,77)$. EGFR usually forms dimers with other members of HER family (including HER1/EGFR/erbB1, HER2/erbB2, HER/ erbB3, and HER4/erbB4) or other EGFRs $(78,79)$. After binding to its ligand, EGFR is auto-phosphorylated at its tyrosine residues, followed by the activation of some downstream signaling pathways, and get involved in various cellular processes such as cell proliferation, apoptosis and survival (78). Gene amplifications or mutations can generate continuously activated EGFR, leading to tumorigenesis $(80,81)$. The prevalence of EGFR mutations in lung adenocarcinoma patients ranges from $10 \%$ to $78 \%$, depending on ethnicity and geographic location, such as $30 \%$ to $40 \%$ in Asian patients and $15 \%$ in white patients $(82,83)$. The vast majority (for more than $90 \%$ ) of activating EGFR mutations are known as either the deletion mutations of Exon 19 or the point mutations of Exon 21 (L858R), and patients with these two mutations are both highly sensitive to EGFR tyrosine kinase inhibitors (TKIs) $(84,85)$. 


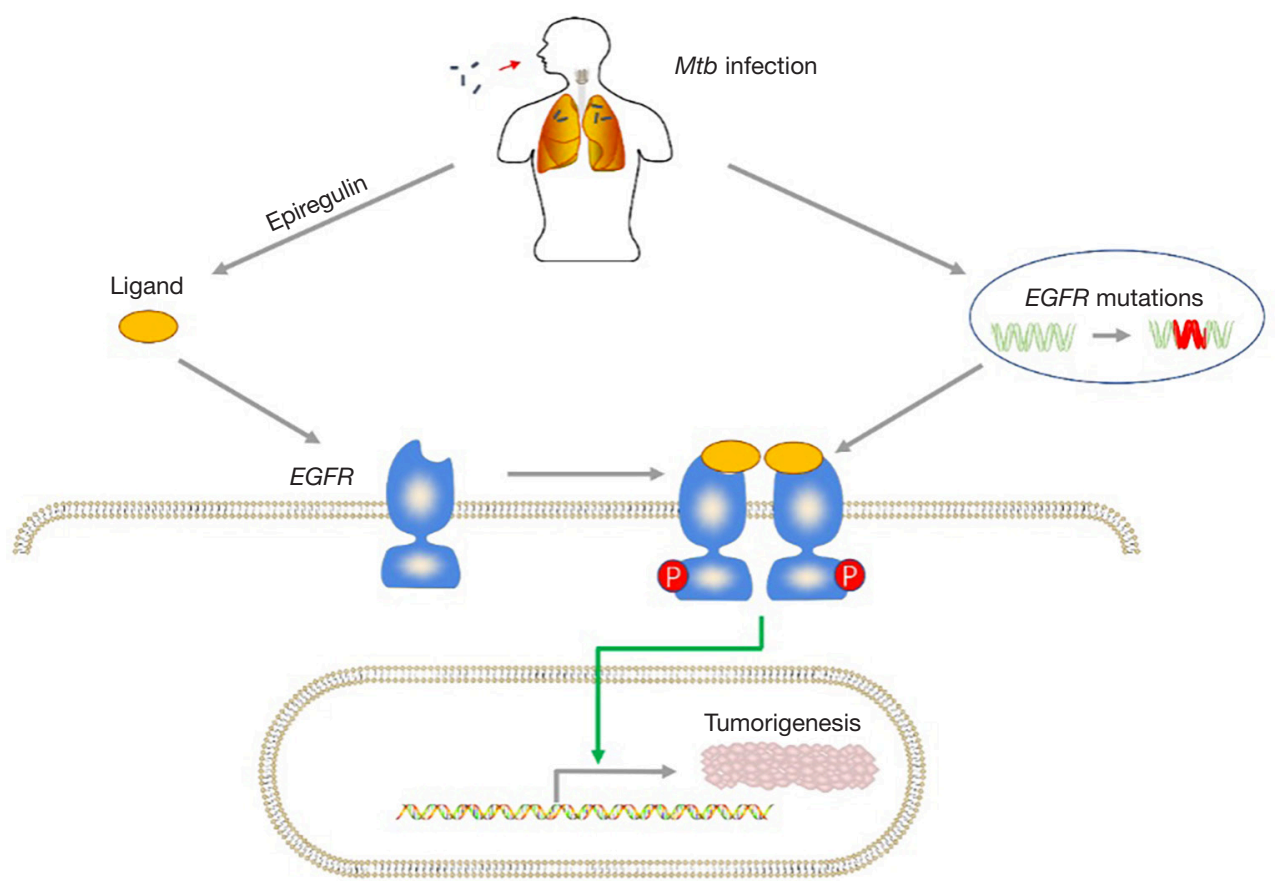

Figure 3 Epidermal growth factor receptor (EGFR) mutations induced by tuberculosis (TB) in lung cancer (LC): EGFR autophosphorylates at their tyrosine residues after binding to their ligands. The activated EGFR activates many downstream signaling pathways, such as cell proliferation, apoptosis, and survival. EGFR mutations can generate continuously activated EGFR, which leads to tumorigenesis. Patients with pre-existing tuberculosis (TB) have an increased frequency of EGFR mutations, and Mycobacterium tuberculosis (MTB)-infected macrophages play a role in the production of epiregulin, a most potent ligand for EGFR, thus promote the occurrence of LC.

A study (86) from South Korea showed that in patients with lung adenocarcinoma, pre-existing TB lesions are significantly associated with increased EGFR mutation rates, particularly exon 19 deletion. The mutation rate in patients with the main mass of the same lobe or different lobes of the ipsilateral lung was significantly higher than that in patients with the main mass of the contralateral lung. In addition, patients treated with EGFR-TKIs for TB-associated adenocarcinoma have poorer treatment response and survival compared with non-TB-associated patients (86). Luo et al. (87) evaluated the correlation of EGFR mutation outcomes available in 275 patients in Taiwan. In their study, a total of 191 patients (69.5\%) had EGFR mutations, and the mutation rate was significantly higher in patients with old PTB lesions than that in nonPTB patients ( $80.6 \%$ vs. $65.5 \%, \mathrm{P}=0.018)$. In addition, they reported a higher rate of exon 19 deletion in patients with older PTB lesions than that in patients without $\mathrm{PTB}$ (68\% vs. $34 \%, \mathrm{P}<0.001$ ). Chang et al. (88) reviewed 8,265 patients and found that a history of PTB was associated with a poor clinical response to EGFR-TKIs in men and a better response in women. The reason why patients with PTB-associated adenocarcinoma have poor response to EGFR-TKIs remains unclear. However, aggressive phenotypes caused by chronic inflammation may be a possible explanation. Nalbandian et al. (41) found that MTB-infected macrophages induce DNA damage nearby and produce a most potent ligand for EGFR, epiregulin, to induce carcinogenesis. Thus, PTB-induced EGFR mutations and epiregulin production maybe also be involved in lung carcinogenesis. Taken together, TB-induced EGFR mutations and epiregulin production maybe also contribute to the carcinogenesis in lung (Figure 3).

\section{The occurrence of PTB during anti-PD-1/PD-L1 therapy}

Immune checkpoint inhibitors (ICIs) are a class of immunotherapy drugs that have made great breakthroughs in the field of tumor therapy in recent years, which is a therapeutic method to kill tumor cells by regulating $\mathrm{T}$ cell activity through a series of pathways such as co-inhibition 
or co-stimulation of signals. Checkpoint inhibitors target cytotoxic T-lymphocyte-associated protein-4 (CTLA-4), PD-1, and PD-L1 were currently approved. Interestingly, the roles of ICIs in infectious diseases have also been studied (89). PTB reactivation is recognized as an adverse reaction that is attributable to anticancer biologics and TNF- $\alpha$ inhibitors (90). PTB recurrences are more common in patients with hematologic malignancies than those with solid tumors. In solid tumors, the reactivation rate of PTB is highest in LC, followed by gastric cancer, breast cancer, liver cancer and colon cancer (90). There are increasing reports of MTB activation during ICIs immunotherapy (91). A study summarized 15 related cases from 12 retrieved articles showed that all the patients were either Caucasians or Asian and aged 49 to 87 years, with a male preponderance, and 5 cases of them were diagnosed as metastatic NSCLC (92).

Most patients infected with MTB may remain a latent state, and only about $10 \%$ of them may develop an active PTB (1). The containment of the infection is mediated by the interaction between cytokines and macrophages and $\mathrm{T}$ lymphocytes (CD4 and CD8) (93). Immune dysfunction (organ transplant patients and patients receiving immunosuppressive therapy) is the most critical risk factor for MTB activation (94). In a mouse model, PD-1-deficient individuals exposed to MTB aerosol were significantly sensitive to MTB infection and high bacterial load accompanied by significantly increased proinflammatory cytokines like IL-1, IL-6, IL-17 (95). Compared with the control group, the survival rate of PD-1-deficient mice was also significantly reduced. These reveal that excessive inflammatory response due to PD-1 dysfunction is detrimental for host to control MTB, while another study shown that the activating immune system through blocking PD-1/PD-L1 can effectively target inhibit certain viral, bacterial, and fungal pathogens by limiting $\mathrm{T}$ cell dysfunction (89). A case report (96) showed that nivolumab (an anti-PD-1antibody immune checkpoint inhibitor) therapy may promote the progression of Mycobacterium abscess disease. In addition, Fujita et al. (97) reported a patient with SCLC developed bacteriologically confirmed PTB after eight cycles of nivolumab administration. Thus, improper interventions of PD-1/PD-L1 function may be detrimental for MTB control, even resulting in PTB reactivation.

There is currently no clear evidence of the need for LTBI screening tests and preventive antituberculosis therapy before immunotherapy. We believe that relevant research is necessary in the future, especially in countries with high TB burdens (92).

\section{Microbial dysbiosis caused by the long-time anti- TB chemotherapy may lead to LC}

Microflora is known to participate in maintaining the homeostasis and the regulation of immune responses in hosts. Although it has been long considered that the healthy lung tissues were sterile, a number of microbial species were found in healthy lung tissues through high-throughput sequencing, the next generation sequencing (NGS) technologies $(98,99)$. The microflora in lung plays essential roles in physiological process in hosts, such as exercising effects on mucosal immunity, promoting the recruitment of neutrophil to induce immune tolerance, affecting the secretion of TLR2-dependent pro-inflammatory cytokines, and the release of an antimicrobial peptide human $\beta$-defensin-2 (hBD2) (100). Brown et al. (101) showed that microbiota enhances respiratory defenses through GM-CSF, whose generation in lung is primed by microbiota through IL-17A in response to infection. GM-CSF signaling can enhance the ability of alveolar macrophages to kill invasive pathogens (101). Due to the invasion of the tumor and the use of cytotoxic drugs, microbial dysbiosis may occurred in LC patients. A study (102) found that MTB related functional pathways were enriched in LC patients through 16S rRNA gene analysis of saliva microbiota. Correspondingly, the long-term anti-TB chemotherapy required makes the longterm detrimental effects on the microbiota (103). It has been widely acknowledged that the interaction between host immunity and external environmental factors, among which microbes is deeply involved in maintaining microecological balance and regulating the immune responses in host to multiple treatment interference, contributes to LC $(104,105)$. Therefore, LC may cause the reactivation of LTBI and increase the susceptibility of PTB by weakening local immunity. The microbial dysbiosis caused by the long-time anti-TB chemotherapy may also lead to the occurrence of LC.

\section{TB may be immunologically related to LC through Bacille Calmette-Guerin (BCG)}

BCG is a live vaccine made from a suspension of attenuated Mycobacterium bovis bacilli and is the only approved vaccine for the prevention of MTB. BCG can activate an innate immune system, macrophages particularly, which is beneficial to be a preventive and therapeutic vaccine in $\mathrm{TB}$ and cancer. 
Trained innate immunity (TI) is acknowledged to be NOD2 receptor dependent. As a cytoplasmic pathogen recognition receptor (PRR), NOD2 receptor recognizes muramyl dipeptide (MDP) from bacterial peptidoglycan (106). MDP triggers NOD2 receptors to increase the release of proinflammatory cytokines such as TNF- $\alpha$, IL- $1 \beta$, and IL-6, resulting in non-specific protection against MTB infection and other non-mycobacterial infections (107-110). Innate immune training occurs in both monocytes and other cells (e.g., NK cells) (111). However, BCG-induced trained innate immunity can still occur in the absence of a NOD receptor, which is thought to help recruit activated macrophages into lung to make the innate immune system hyperactivated after subcutaneous vaccination (107). Intravesical BCG has been seen as one of the most effective therapies for non-muscular invasive bladder cancer (NMIBC), the most common type (75\%) of bladder cancer, since firstly reported by Morales et al. in 1976 (112,113). A recent study (114) enrolled 1,540 BCG vaccinated participants and 1,423 placebo recipients showed a similar overall incidence of cancers, including lymphoma and leukemia, among BCG vaccinators and placebo recipients (HR: 0.8; 95\% CI: 0.7-1.0). However, after adjusting for factors such as gender, region, alcohol use, smoking and history of PTB, the incidence of LC in the BCG vaccinated group (18.2 per 100,000 person-years) was significantly lower than that in the placebo group (45.4 per 100,000 person-years) (HR: 0.4; 95\% CI: 0.2-0.7; $\mathrm{P}=0.005$ ). BCG is the only MTB protective vaccine and the gold standard adjuvant in the treatment of NMIBC, suggesting that there are some undefined immunosuppressive mechanisms between PTB and LC, which may be one of the future research directions.

\section{Conclusions}

Epidemiological studies have confirmed the relationship between TB and LC. Chronic inflammatory stimulation, immune abnormality, scar formation, gene mutation and drug influence caused by MTB may be related to the occurrence of LC. LC and reduced immunity during treatment may also increase the risk of LTBI activation or new MTB infections. However, the underlying mechanisms by which the two diseases interact have not been fully elucidated. The rapid development of immunotherapy has brought the promise of treatment for patients with advanced LC, but the subsequent recurrence of PTB has attracted the attention of researchers. Existing researches are mainly focused on developed countries and data from areas with the double burden of PTB and LC are still lacking, therefore, more clinical studies in different epidemiological Settings are needed to elucidate the underlying mechanisms of influence between these two diseases.

\section{Acknowledgments}

Funding: This study was supported in part by Fund of Shanghai Pulmonary Hospital (fkzr2027, fk1945, FKLY20017).

\section{Footnote}

Reporting Checklist: The authors have completed the Narrative Review reporting checklist. Available at https:// dx.doi.org/10.21037/tlcr-21-465

Peer Review File: Available at https://dx.doi.org/10.21037/ tlcr-21-465

Conflicts of Interest: All authors have completed the ICMJE uniform disclosure form (available at https://dx.doi. org/10.21037/tlcr-21-465). The authors have no conflicts of interest to declare.

Ethical Statement: The authors are accountable for all aspects of the work in ensuring that questions related to the accuracy or integrity of any part of the work are appropriately investigated and resolved.

Open Access Statement: This is an Open Access article distributed in accordance with the Creative Commons Attribution-NonCommercial-NoDerivs 4.0 International License (CC BY-NC-ND 4.0), which permits the noncommercial replication and distribution of the article with the strict proviso that no changes or edits are made and the original work is properly cited (including links to both the formal publication through the relevant DOI and the license). See: https://creativecommons.org/ licenses/by-nc-nd/4.0/.

\section{References}

1. Global tuberculosis report 2020. Geneva: World Health Organization. Available online: https://apps.who.int/iris/ handle/10665/336069

2. World Health Organization (WHO). World cancer report 2020. 2020. Available online: https://www.iarc.fr/cards_ 
page/world-cancer-report

3. Molina JR, Yang P, Cassivi SD, et al. Non-small cell lung cancer: epidemiology, risk factors, treatment, and survivorship. Mayo Clin Proc 2008;83:584-94.

4. Lantuejoul S, Fernandez-Cuesta L, Damiola F, et al. New molecular classification of large cell neuroendocrine carcinoma and small cell lung carcinoma with potential therapeutic impacts. Transl Lung Cancer Res 2020;9:2233-44.

5. Khan P, Siddiqui JA, Lakshmanan I, et al. RNA-based therapies: A cog in the wheel of lung cancer defense. Mol Cancer 2021;20:54.

6. Siegel RL, Miller KD, Jemal A. Cancer statistics, 2020. CA Cancer J Clin 2020;70:7-30.

7. Siegel RL, Miller KD, Jemal A. Cancer statistics, 2019. CA Cancer J Clin 2019;69:7-34.

8. Plummer M, de Martel C, Vignat J, et al. Global burden of cancers attributable to infections in 2012: a synthetic analysis. Lancet Glob Health 2016;4:e609-16.

9. Leung CY, Huang HL, Rahman MM, et al. Cancer incidence attributable to tuberculosis in 2015: global, regional, and national estimates. BMC Cancer 2020;20:412.

10. Cicenas S, Vencevicius V. Lung cancer in patients with tuberculosis. World J Surg Oncol 2007;5:22.

11. Ho JC, Leung CC. Management of co-existent tuberculosis and lung cancer. Lung Cancer 2018;122:83-7.

12. Everatt R, Kuzmickiene I, Davidaviciene E, et al. Incidence of lung cancer among patients with tuberculosis: a nationwide cohort study in Lithuania. Int J Tuberc Lung Dis 2016;20:757-63.

13. Oh CM, Roh YH, Lim D, et al. Pulmonary Tuberculosis is Associated with Elevated Risk of Lung cancer in Korea: The Nationwide Cohort Study. J Cancer 2020;11:1899-906.

14. Wu CY, Hu HY, Pu CY, et al. Pulmonary tuberculosis increases the risk of lung cancer: a population-based cohort study. Cancer 2011;117:618-24.

15. Yu YH, Liao CC, Hsu WH, et al. Increased lung cancer risk among patients with pulmonary tuberculosis: a population cohort study. J Thorac Oncol 2011;6:32-7.

16. Zheng W, Blot WJ, Liao ML, et al. Lung cancer and prior tuberculosis infection in Shanghai. Br J Cancer 1987;56:501-4.

17. Shiels MS, Albanes D, Virtamo J, et al. Increased risk of lung cancer in men with tuberculosis in the alphatocopherol, beta-carotene cancer prevention study. Cancer Epidemiol Biomarkers Prev 2011;20:672-8.
18. Liang HY, Li XL, Yu XS, et al. Facts and fiction of the relationship between preexisting tuberculosis and lung cancer risk: a systematic review. Int J Cancer 2009;125:2936-44.

19. Brenner DR, McLaughlin JR, Hung RJ. Previous lung diseases and lung cancer risk: a systematic review and meta-analysis. PLoS One 2011;6:e17479.

20. Engels EA, Shen M, Chapman RS, et al. Tuberculosis and subsequent risk of lung cancer in Xuanwei, China. Int J Cancer 2009;124:1183-7.

21. Heuvers ME, Aerts JG, Hegmans JP, et al. History of tuberculosis as an independent prognostic factor for lung cancer survival. Lung Cancer 2012;76:452-6.

22. Littman AJ, Thornquist MD, White E, et al. Prior lung disease and risk of lung cancer in a large prospective study. Cancer Causes Control 2004;15:819-27.

23. Su VY, Yen YF, Pan SW, et al. Latent Tuberculosis Infection and the Risk of Subsequent Cancer. Medicine (Baltimore) 2016;95:e2352.

24. Hofman A, Breteler MM, van Duijn CM, et al. The Rotterdam Study: 2010 objectives and design update. Eur J Epidemiol 2009;24:553-72.

25. Moreira AL, Wang J, Tsenova-Berkova L, et al. Sequestration of Mycobacterium tuberculosis in tight vacuoles in vivo in lung macrophages of mice infected by the respiratory route. Infect Immun 1997;65:305-8.

26. van der Wel N, Hava D, Houben D, et al. M. tuberculosis and $M$. leprae translocate from the phagolysosome to the cytosol in myeloid cells. Cell 2007;129:1287-98.

27. Russell DG, Cardona PJ, Kim MJ, et al. Foamy macrophages and the progression of the human tuberculosis granuloma. Nat Immunol 2009;10:943-8.

28. Bickett TE, Karam SD. Tuberculosis-Cancer Parallels in Immune Response Regulation. Int J Mol Sci 2020;21:6136.

29. Alatas F, Alatas O, Metintas M, et al. Vascular endothelial growth factor levels in active pulmonary tuberculosis. Chest 2004;125:2156-9.

30. Engels EA. Inflammation in the development of lung cancer: epidemiological evidence. Expert Rev Anticancer Ther 2008;8:605-15.

31. Lin WW, Karin M. A cytokine-mediated link between innate immunity, inflammation, and cancer. J Clin Invest 2007;117:1175-83.

32. Karin M. Nuclear factor-kappaB in cancer development and progression. Nature 2006;441:431-6.

33. Coussens LM, Werb Z. Inflammation and cancer. Nature 
2002;420:860-7.

34. Saka D, Gökalp M, Piyade B, et al. Mechanisms of T-Cell Exhaustion in Pancreatic Cancer. Cancers (Basel) 2020;12:2274.

35. Xia L, Liu Y, Wang Y. PD-1/PD-L1 Blockade Therapy in Advanced Non-Small-Cell Lung Cancer: Current Status and Future Directions. Oncologist 2019;24:S31-41.

36. Doroshow DB, Sanmamed MF, Hastings K, et al. Immunotherapy in Non-Small Cell Lung Cancer: Facts and Hopes. Clin Cancer Res 2019;25:4592-602.

37. Rous P, Kidd JG. CONDITIONAL NEOPLASMS AND SUBTHRESHOLD NEOPLASTIC STATES : A STUDY OF THE TAR TUMORS OF RABBITS. J Exp Med 1941;73:365-90.

38. Panieri E, Santoro MM. ROS homeostasis and metabolism: a dangerous liason in cancer cells. Cell Death Dis 2016;7:e2253.

39. Stanicka J, Russell EG, Woolley JF, et al. NADPH oxidase-generated hydrogen peroxide induces DNA damage in mutant FLT3-expressing leukemia cells. J Biol Chem 2015;290:9348-61.

40. Moloney JN, Cotter TG. ROS signalling in the biology of cancer. Semin Cell Dev Biol 2018;80:50-64.

41. Nalbandian A, Yan BS, Pichugin A, et al. Lung carcinogenesis induced by chronic tuberculosis infection: the experimental model and genetic control. Oncogene 2009;28:1928-38.

42. Yu YY, Pinsky PF, Caporaso NE, et al. Lung cancer risk following detection of pulmonary scarring by chest radiography in the prostate, lung, colorectal, and ovarian cancer screening trial. Arch Intern Med 2008;168:2326-32; discussion 2332.

43. Woo SJ, Kim Y, Jung H, et al. Tuberculous Fibrosis Enhances Tumorigenic Potential via the NOX4Autophagy Axis. Cancers (Basel) 2021;13:687.

44. Van Overmeire E, Laoui D, Keirsse J, et al. Mechanisms driving macrophage diversity and specialization in distinct tumor microenvironments and parallelisms with other tissues. Front Immunol 2014;5:127.

45. Porrello A, Leslie PL, Harrison EB, et al. Factor XIIIAexpressing inflammatory monocytes promote lung squamous cancer through fibrin cross-linking. Nat Commun 2018;9:1988.

46. Sapalidis K, Sardeli C, Pavlidis E, et al. Scar tissue to lung cancer; pathways and treatment. J Cancer 2019;10:810-8.

47. Hasan Z, Cliff JM, Dockrell HM, et al. CCL2 responses to Mycobacterium tuberculosis are associated with disease severity in tuberculosis. PLoS One 2009;4:e8459.

48. Qian BZ, Li J, Zhang H, et al. CCL2 recruits inflammatory monocytes to facilitate breast-tumour metastasis. Nature 2011;475:222-5.

49. Harney AS, Arwert EN, Entenberg D, et al. Real-Time Imaging Reveals Local, Transient Vascular Permeability, and Tumor Cell Intravasation Stimulated by TIE2hi Macrophage-Derived VEGFA. Cancer Discov 2015;5:932-43.

50. Mitchem JB, Brennan DJ, Knolhoff BL, et al. Targeting tumor-infiltrating macrophages decreases tumorinitiating cells, relieves immunosuppression, and improves chemotherapeutic responses. Cancer Res 2013;73:1128-41.

51. Wyckoff J, Wang W, Lin EY, et al. A paracrine loop between tumor cells and macrophages is required for tumor cell migration in mammary tumors. Cancer Res 2004;64:7022-9.

52. Chanmee T, Ontong P, Konno K, et al. Tumorassociated macrophages as major players in the tumor microenvironment. Cancers (Basel) 2014;6:1670-90.

53. Murray PJ. Macrophage Polarization. Annu Rev Physiol 2017;79:541-66.

54. Laoui D, Movahedi K, Van Overmeire E, et al. Tumorassociated macrophages in breast cancer: distinct subsets, distinct functions. Int J Dev Biol 2011;55:861-7.

55. Mantovani A, Sozzani S, Locati M, et al. Macrophage polarization: tumor-associated macrophages as a paradigm for polarized M2 mononuclear phagocytes. Trends Immunol 2002;23:549-55.

56. Zhang $M$, He $Y$, Sun $X$, et al. A high $M 1 / M 2$ ratio of tumor-associated macrophages is associated with extended survival in ovarian cancer patients. J Ovarian Res 2014;7:19.

57. Henze AT, Mazzone M. The impact of hypoxia on tumor-associated macrophages. J Clin Invest 2016;126:3672-9.

58. van Dalen FJ, van Stevendaal MHME, Fennemann FL, et al. Molecular Repolarisation of Tumour-Associated Macrophages. Molecules 2018;24:9.

59. Wang LX, Zhang SX, Wu HJ, et al. M2b macrophage polarization and its roles in diseases. J Leukoc Biol 2019;106:345-58.

60. Zheng X, Turkowski K, Mora J, et al. Redirecting tumorassociated macrophages to become tumoricidal effectors as a novel strategy for cancer therapy. Oncotarget 2017;8:48436-52.

61. Lin $\mathrm{Y}, \mathrm{Xu} \mathrm{J}$, Lan H. Tumor-associated macrophages in 
tumor metastasis: biological roles and clinical therapeutic applications. J Hematol Oncol 2019;12:76.

62. Mills CD. M1 and M2 Macrophages: Oracles of Health and Disease. Crit Rev Immunol 2012;32:463-88.

63. Lugo-Villarino G, Vérollet C, Maridonneau-Parini I, et al. Macrophage polarization: convergence point targeted by mycobacterium tuberculosis and HIV. Front Immunol 2011;2:43.

64. Yagnik G, Rutowski MJ, Shah SS, et al. Stratifying nonfunctional pituitary adenomas into two groups distinguished by macrophage subtypes. Oncotarget 2019;10:2212-23.

65. Dong P, Ma L, Liu L, et al. CD $86^{+} / \mathrm{CD} 206^{+}$, Diametrically Polarized Tumor-Associated Macrophages, Predict Hepatocellular Carcinoma Patient Prognosis. Int J Mol Sci 2016;17:320.

66. Mantovani A, Allavena P. The interaction of anticancer therapies with tumor-associated macrophages. J Exp Med 2015;212:435-45.

67. Xu M, Liu M, Du X, et al. Intratumoral Delivery of IL-21 Overcomes Anti-Her2/Neu Resistance through Shifting Tumor-Associated Macrophages from M2 to M1 Phenotype. J Immunol 2015;194:4997-5006.

68. Boutilier AJ, Elsawa SF. Macrophage Polarization States in the Tumor Microenvironment. Int J Mol Sci 2021;22:6995.

69. Murray PJ, Wynn TA. Obstacles and opportunities for understanding macrophage polarization. J Leukoc Biol 2011;89:557-63.

70. Verbon A, Juffermans N, Van Deventer SJ, et al. Serum concentrations of cytokines in patients with active tuberculosis (TB) and after treatment. Clin Exp Immunol 1999;115:110-3.

71. Raju B, Hoshino Y, Belitskaya-Lévy I, et al. Gene expression profiles of bronchoalveolar cells in pulmonary TB. Tuberculosis (Edinb) 2008;88:39-51.

72. Ruano MJ, Hernández-Hernando S, Jiménez A, et al. Nitric oxide-induced epidermal growth factor-dependent phosphorylations in A431 tumour cells. Eur J Biochem 2003;270:1828-37.

73. Benoit M, Desnues B, Mege JL. Macrophage polarization in bacterial infections. J Immunol 2008;181:3733-9.

74. Columba-Cabezas S, Serafini B, Ambrosini E, et al. Induction of macrophage-derived chemokine/CCL22 expression in experimental autoimmune encephalomyelitis and cultured microglia: implications for disease regulation. J Neuroimmunol 2002;130:10-21.

75. Bloch O, Crane CA, Kaur R, et al. Gliomas promote immunosuppression through induction of B7-H1 expression in tumor-associated macrophages. Clin Cancer Res 2013;19:3165-75.

76. Jett JR, Carr LL. Targeted therapy for non-small cell lung cancer. Am J Respir Crit Care Med 2013;188:907-12.

77. Pao W, Miller V, Zakowski M, et al. EGF receptor gene mutations are common in lung cancers from "never smokers" and are associated with sensitivity of tumors to gefitinib and erlotinib. Proc Natl Acad Sci U S A 2004;101:13306-11.

78. Nan X, Xie C, Yu X, et al. EGFR TKI as first-line treatment for patients with advanced EGFR mutationpositive non-small-cell lung cancer. Oncotarget 2017;8:75712-26.

79. Yu X, Sharma KD, Takahashi T, et al. Ligand-independent dimer formation of epidermal growth factor receptor (EGFR) is a step separable from ligand-induced EGFR signaling. Mol Biol Cell 2002;13:2547-57.

80. Tan CS, Gilligan D, Pacey S. Treatment approaches for EGFR-inhibitor-resistant patients with non-small-cell lung cancer. Lancet Oncol 2015;16:e447-59.

81. Liu H, Zhang B, Sun Z. Spectrum of EGFR aberrations and potential clinical implications: insights from integrative pan-cancer analysis. Cancer Commun (Lond) 2020;40:43-59.

82. Shi Y, Au JS, Thongprasert S, et al. A prospective, molecular epidemiology study of EGFR mutations in Asian patients with advanced non-small-cell lung cancer of adenocarcinoma histology (PIONEER). J Thorac Oncol 2014;9:154-62.

83. Tfayli AH, Fakhri GB, Al Assaad MS. Prevalence of the epidermal growth factor receptor mutations in lung adenocarcinoma patients from the Middle East region. Ann Thorac Med 2019;14:173-8.

84. Lynch TJ, Bell DW, Sordella R, et al. Activating mutations in the epidermal growth factor receptor underlying responsiveness of non-small-cell lung cancer to gefitinib. N Engl J Med 2004;350:2129-39.

85. Paez JG, Jänne PA, Lee JC, et al. EGFR mutations in lung cancer: correlation with clinical response to gefitinib therapy. Science 2004;304:1497-500.

86. Hwang IK, Paik SS, Lee SH. Impact of Pulmonary Tuberculosis on the EGFR Mutational Status and Clinical Outcome in Patients with Lung Adenocarcinoma. Cancer Res Treat 2019;51:158-68.

87. Luo $\mathrm{YH}, \mathrm{Wu} \mathrm{CH}, \mathrm{Wu} \mathrm{WS}$, et al. Association between tumor epidermal growth factor receptor mutation and pulmonary tuberculosis in patients with adenocarcinoma 
of the lungs. J Thorac Oncol 2012;7:299-305.

88. Chang CH, Lee CH, Ho CC, et al. Gender-based impact of epidermal growth factor receptor mutation in patients with nonsmall cell lung cancer and previous tuberculosis. Medicine (Baltimore) 2015;94:e444.

89. Sharpe AH, Wherry EJ, Ahmed R, et al. The function of programmed cell death 1 and its ligands in regulating autoimmunity and infection. Nat Immunol 2007;8:239-45.

90. Dobler CC, Cheung K, Nguyen J, et al. Risk of tuberculosis in patients with solid cancers and haematological malignancies: a systematic review and meta-analysis. Eur Respir J 2017;50:1700157.

91. Dobler CC. Biological agents and tuberculosis: risk estimates and screening strategies. Int J Rheum Dis 2015;18:264-7.

92. Suliman AM, Bek SA, Elkhatim MS, et al. Tuberculosis following programmed cell death receptor-1 (PD-1) inhibitor in a patient with non-small cell lung cancer. Case report and literature review. Cancer Immunol Immunother 2021;70:935-44.

93. van Crevel R, Ottenhoff TH, van der Meer JW. Innate immunity to Mycobacterium tuberculosis. Clin Microbiol Rev 2002;15:294-309.

94. Ai JW, Ruan QL, Liu QH, et al. Updates on the risk factors for latent tuberculosis reactivation and their managements. Emerg Microbes Infect 2016;5:e10.

95. Lázár-Molnár E, Chen B, Sweeney KA, et al.

Programmed death-1 (PD-1)-deficient mice are extraordinarily sensitive to tuberculosis. Proc Natl Acad Sci U S A 2010;107:13402-7.

96. Ishii S, Tamiya A, Taniguchi $\mathrm{Y}$, et al. Improvement of Mycobacterium abscessus Pulmonary Disease after Nivolumab Administration in a Patient with Advanced Non-small Cell Lung Cancer. Intern Med 2018;57:3625-9.

97. Fujita K, Terashima T, Mio T. Anti-PD1 Antibody Treatment and the Development of Acute Pulmonary Tuberculosis. J Thorac Oncol 2016;11:2238-40.

98. Dickson RP, Huffnagle GB. The Lung Microbiome: New Principles for Respiratory Bacteriology in Health and Disease. PLoS Pathog 2015;11:e1004923.

99. Dickson RP, Martinez FJ, Huffnagle GB. The role of the microbiome in exacerbations of chronic lung diseases.

Lancet 2014;384:691-702.

100. Enaud R, Prevel R, Ciarlo E, et al. The Gut-Lung Axis in Health and Respiratory Diseases: A Place for InterOrgan and Inter-Kingdom Crosstalks. Front Cell Infect Microbiol 2020;10:9.
101. Brown RL, Sequeira RP, Clarke TB. The microbiota protects against respiratory infection via GM-CSF signaling. Nat Commun 2017;8:1512.

102. Yang J, Mu X, Wang Y, et al. Dysbiosis of the Salivary Microbiome Is Associated With Nonsmoking Female Lung Cancer and Correlated With Immunocytochemistry Markers. Front Oncol 2018;8:520.

103. Naidoo CC, Nyawo GR, Wu BG, et al. The microbiome and tuberculosis: state of the art, potential applications, and defining the clinical research agenda. Lancet Respir Med 2019;7:892-906.

104. Brandi G, Frega G. Microbiota: Overview and Implication in Immunotherapy-Based Cancer Treatments. Int J Mol Sci 2019;20:2699.

105.Liu NN, Ma Q, Ge Y, et al. Microbiome dysbiosis in lung cancer: from composition to therapy. NPJ Precis Oncol $2020 ; 4: 33$.

106. Inohara N, Ogura Y, Fontalba A, et al. Host recognition of bacterial muramyl dipeptide mediated through NOD2. Implications for Crohn's disease. J Biol Chem 2003;278:5509-12.

107. Bickett TE, McLean J, Creissen E, et al. Characterizing the BCG Induced Macrophage and Neutrophil Mechanisms for Defense Against Mycobacterium tuberculosis. Front Immunol 2020;11:1202.

108. Kleinnijenhuis J, Quintin J, Preijers F, et al. Bacille Calmette-Guerin induces NOD2-dependent nonspecific protection from reinfection via epigenetic reprogramming of monocytes. Proc Natl Acad Sci U S A 2012;109:17537-42.

109. Kaufmann E, Sanz J, Dunn JL, et al. BCG Educates Hematopoietic Stem Cells to Generate Protective Innate Immunity against Tuberculosis. Cell 2018;172:176-190.e19.

110.Jayasingam SD, Citartan M, Thang TH, et al. Evaluating the Polarization of Tumor-Associated Macrophages Into M1 and M2 Phenotypes in Human Cancer Tissue: Technicalities and Challenges in Routine Clinical Practice. Front Oncol 2019;9:1512.

111.Kleinnijenhuis J, Quintin J, Preijers F, et al. BCGinduced trained immunity in NK cells: Role for non-specific protection to infection. Clin Immunol 2014;155:213-9.

112. Morales A, Eidinger D, Bruce AW. Intracavitary Bacillus Calmette-Guerin in the treatment of superficial bladder tumors. J Urol 1976;116:180-3.

113.Han J, Gu X, Li Y, et al. Mechanisms of BCG in the 
treatment of bladder cancer-current understanding and the prospect. Biomed Pharmacother 2020;129:110393.

114. Usher NT, Chang S, Howard RS, et al. Association of
BCG Vaccination in Childhood With Subsequent Cancer Diagnoses: A 60-Year Follow-up of a Clinical Trial. JAMA Netw Open 2019;2:e1912014.

Cite this article as: Xiong K, Sun W, He Y, Fan L. Advances in molecular mechanisms of interaction between Mycobacterium tuberculosis and lung cancer: a narrative review. Transl Lung Cancer Res 2021;10(10):4012-4026. doi: 10.21037/tlcr-21-465 